\title{
A RESSIGNIFICAÇÃO DA FORMAÇÃO ACADÊMICA NA CONSTRUÇÃO DA VIDA PROFISSIONAL
}

\section{1- André Luis Silva*}

Doutorando em Administração de Empresas pela Fundação Getúlio Vargas (FGV/EAESP), Brasil. emailspara@gmail.com

http://lattes.cnpq.br/1257050194773665

\section{2- Márcia de Freitas Duarte}

Doutoranda em Administração de Empresas pela Fundação Getúlio Vargas (FGV/EAESP), Brasil. marcia.freitas.duarte@gmail.com

http://lattes.cnpq.br/6011463057600858 


\section{A RESSIGNIFICAÇÃO DA FORMAÇÃO ACADÊMICA NA CONSTRUÇÃO DA VIDA PROFISSIONAL}

\section{RESUMO}

Neste artigo teve-se por objetivo compreender como o elemento formação acadêmica foi transformado em uma estratégia de enfrentamento, que auxiliou os funcionários que vivenciaram, no ano de 2006, a operação de aquisição de uma instituição financeira internacional onde trabalhavam, por outra instituição nacional, a lidarem com os impactos dessa abrupta mudança no ambiente de trabalho, conseguindo, assim, ressignificar o sentido da própria carreira. A pesquisa é qualitativa, descritiva, com corte temporal seccional e perspectiva longitudinal. Os dados foram coletados por meio de entrevistas semiestruturadas e interpretados à luz da técnica de análise de conteúdo. Concluiu-se que os funcionários lançaram mão da formação acadêmica como uma estratégia de enfrentamento frente à operação de aquisição, ressignificando, assim, o sentido da situação e da própria carreira para conseguirem permanecer trabalhando na instituição adquirente. Ou seja, surgiram novas maneiras de conceber as significações da formação acadêmica na construção da vida profissional. Aponta-se que, possivelmente, é a partir de como vem sendo realizado o processo de ensino de graduação no Brasil, que a formação acadêmica deixa de ser significada apenas como algo que assegura pré-requisitos para inserção no mercado de trabalho e/ou manutenção da carreira. Neste trabalho, a formação acadêmica se mostrou uma estratégia de enfrentamento, pela qual se faz possível superar os impactos gerados pelas transformações organizacionais.

\section{Palavras-Chave}

Carreira, Estratégia de Enfrentamento, Formação Acadêmica, Relações de Trabalho.

\section{THE REFRAMING OF UNIVERSITY EDUCATION IN THE CONSTRUCTION OF PROFESSIONAL LIFE}

\section{ABSTRACT}

In this paper, the objective was to understand how the element university education was transformed in a coping strategy that helped employees who lived in the year 2006, the acquisition of a financial institution they worked for another national institution, to deal with the impacts of this abrupt change in the workplace, getting thus reframing the meaning of his career. The research is qualitative, descriptive, with temporal and sectional cut, with a longitudinal perspective. Data were collected through interviews, and interpreted using the technique of content analysis. It was concluded that the employees had resorted to university education as a coping strategy against the acquisition, ressignifying thus the sense of the situation and their own career to be able to stay working in the acquiring institution. That is, new ways of conceiving the meaning of the university education in the construction of professional life. It's pointed that is possibly from the way that is being done the process of university education in Brazil, that academic education is no longer just meant as something that provides prerequisites for entering the labor market and/or maintenance of career, because in this article, this proved to be a coping strategy by which it is possible to overcome the impacts of these organizational changes.

\section{Keywords}

Career, Education, Coping Strategy, University Education, Labor Relations. 


\section{Introdução}

Uma metáfora parece traduzir, com excelência, as expectativas que a sociedade e as organizações têm em relação aos trabalhadores contemporâneos: "o homem camaleão" (Caldas \& Tonelli, 1998). Esta metáfora traz consigo um ideal de capacidade adaptativa ao ambiente no qual a pessoa se vê diante da necessidade de ser flexível, maleável e assumir quantas estratégias de enfrentamento forem necessárias para sua sobrevivência social e no mundo do trabalho.

Surge um contexto de relações ambíguas, onde o ambiente organizacional reflete a complexidade da sociedade que, por sua vez, também sofre influências das organizações. Inseridas nesse contexto, permeado por abruptas e constantes mudanças, estão as pessoas em seus ambientes de trabalho, tendo de lidar com a necessidade de enfrentar as mais diversas situações para manterem seus empregos. Ou seja, pessoas frente à necessidade de desenvolver novas formas de agir, pensar e sentir o seu fazer, a fim de se adequarem às situações vivenciadas na dimensão profissional de suas vidas.

Chama atenção o fato de que a formação acadêmica, por vezes, é um dos fatores que viabilizam esta adequação, pois se percebe que a formação superior vem sendo compreendida, nas últimas décadas, como um pré-requisito elementar não só para inserção no mercado de trabalho, mas, sobremaneira, para a manutenção da própria carreira. Este fato nos leva a considerar que os processos de mudança organizacional, ao impactarem as pessoas, criando-lhes a necessidade de adaptar-se à nova realidade, atuam como gatilhos capazes de fazerem-nas repensar sua formação acadêmica, a fim de lidar com as mudanças organizacionais. Isto é, são gatilhos capazes de fazer emergir nas pessoas a necessidade de tomar novas decisões e escolhas em relação às suas vidas profissionais, para que, assim, consigam enfrentar as abruptas transformações geradas no ambiente de trabalho.

Há de se reconhecer que, em relação ao processo de enfrentamento realizado pelas pessoas frente às situações adversas da vida, o movimento da psicologia positiva apresenta o conceito de resiliência humana, o qual considera que o ser humano é capaz de mobilizar fatores de proteção internos e externos que, ao serem transformados em estratégias de enfrentamentos, amenizam os impactos dessas situações sobre si (Lazarus \& Folkman, 1984). Isto porque, ao lançar mão das estratégias de enfrentamento, a pessoa ganha condições de reconfigurar o sentido da situação e, assim, consegue não só reconhecer o contexto adverso, mas, sobretudo, administrar a própria subjetividade e flexibilizar seu comportamento para se defender (Barlach \& Malvezzi, 2010).

Compreendendo o propósito do processo de enfrentamento realizado pelas pessoas frente às situações adversas e considerando que a formação acadêmica é um elemento utilizado para lidar com as transformações organizacionais, compreendemos que esta formação não pode ser entendida apenas como algo que assegura pré-requisitos profissionais. Isto porque, parece ser também um elemento passível de ser transformado em uma estratégia de enfrentamento, com a qual as pessoas amenizam os impactos gerados pelos processos de mudança nas organizações e, assim, conseguem reconfigurar a concepção de carreira. Dessa forma, parece-nos apropriado o estudo empírico desta questão, ao levantarmos a seguinte pergunta: "Como as pessoas transformam a formação acadêmica em uma estratégia de enfrentamento, para lidarem com as abruptas mudanças vivenciadas no ambiente de trabalho e, assim, conseguem ressignificar o sentido da própria carreira?" A busca por esta compreensão é, portanto, o objetivo desta pesquisa.

Neste trabalho, utilizaremos como fonte empírica de dados, relatos de funcionários que vivenciaram, no ano de 2006, a operação de aquisição da instituição financeira internacional em que trabalhavam, por outra instituição nacional, pois buscaremos compreender como eles lançaram mão de suas formações acadêmicas para enfrentarem esta situação adversa e, assim, permanecerem desenvolvendo suas carreiras na instituição adquirente.

Entendemos que uma das principais justificativas para se buscar atingir o objetivo deste trabalho provém da possibilidade de se compreender, pela intersecção de preceitos teóricos e dados empíricos, a capacidade das pessoas superarem as condições adversas vivenciadas em ambientes de trabalho, por meio da formação acadêmica, uma vez entendida como um elemento passível de ser transformado em uma estratégia de enfrentamento, que dá condições para as pessoas desenvolverem novas significações e maneiras de pensar e sentir o seu fazer na vida profissional.

Incluindo esta introdução, o trabalho está organizado em seis seções. Inicialmente, apresentamos os conceitos envolvidos no processo de enfrentamento realizado pelas pessoas frente às situações adversas. 
Em seguida, delineamos uma noção contemporânea de carreira para abranger as principais transformações que vêm impactando a concepção de vida profissional. Posteriormente, indicamos os procedimentos metodológicos adotados para realização do estudo. A partir de então, são apresentados e interpretados os relatos dos participantes da pesquisa à luz da fundamentação teórica. Por fim, registramos as conclusões deste estudo, indicando novos contornos ao elemento formação acadêmica, bem como apontamos as limitações do trabalho e direções para futuras pesquisas por meio de uma pauta de estudos, realizada a partir da justificativa e finalidade primordial deste trabalho.

\section{Enfrentando Situações Adversas em Contexto Organizacional}

Para enfrentarem as situações adversas da vida, inclusive as vivenciadas em contextos organizacionais, as pessoas, por vezes, demonstram a capacidade de administrar a própria subjetividade e de compreender a situação para se defender. Esta capacidade é denominada, pelo movimento da psicologia positiva como o fenômeno da resiliência humana, que está alicerçado nos fatores de proteção internos - denominado de coping - e externos - denominado de buffers - que a pessoa lança mão frente a um fator de risco (Barlach, 2005).

Falar em fatores de proteção é considerar que as pessoas são capazes de enfrentar situações adversas mobilizando forças internas e externas que as auxiliam a minimizar os efeitos negativos do risco vivenciado sobre si. Ou seja, os fatores de proteção atuam na redução dos impactos gerados nas pessoas pelas adversidades, tais como o desequilíbrio emocional, pois as protegem e Ihes criam condições para o enfrentamento do fator de risco (Cowan, Cowan \& Schulz, 1996; Barlach, Limongi-França \& Malvezzi, 2008). Por exemplo, alguns dos fatores de proteção internos e externos que as pessoas possam a vir lançar mão para enfrentarem uma situação adversa abrangem elementos como: a autonomia do indivíduo; sua autoestima; autodeterminação; respeito; reconhecimento; participação da família; amigos; esperança; delimitação de significados para a vida; a preservação de sua identidade; as crenças individuais; autoafirmação; e fé (Job, 2003).

Mas o que chama atenção é o fato de que as pessoas enfrentam as adversidades com o objetivo de não sucumbirem à situação. Ou seja, o propósito maior de um processo de enfrentamento é dar condições para a pessoa se fortalecer frente à situação adversa. Inusitado é que este fortalecimento ocorre quando a pessoa combina seus fatores de proteção internos e externos e, por conseguinte, consegue utilizá-los por meio de estratégias de enfrentamento que agem e intervêm na situação adversa (Lazarus \& Folkman, 1984). Isto é denominado como o processo de transformação dos fatores de proteção em mecanismos de defesa, e ocorre quando a pessoa atribui uma funcionalidade aos seus fatores de proteção, internos e/ou externos, e, por conseguinte, lança mão para lidar com o fator de risco que lhe causa desequilíbrio emocional (Silva, 2010).

É necessário compreender que o desequilíbrio emocional está associado ao fato de que a pessoa, ao se deparar com um processo de mudança permeado por circunstâncias adversas a serem vivenciadas, tem alterada a sua relação com ambiente no qual ela está inserida. Esta situação evoca o restabelecimento de seu equilíbrio emocional que, por sua vez, advém dos mecanismos de defesa que a pessoa usa para lidar com a situação. Isto ocorre pelo fato de tais mecanismos corresponderem à série de estratégias de enfrentamento flexíveis e propositais que a pessoa desenvolve a partir de aspectos individuais, psicológicos e ambientais, e, por conseguinte, lança mão para enfrentar as situações que Ihe causam desequilíbrio emocional (Lazarus \& Folkman, 1984). Por fim, a pessoa, ao fazer uso de seus mecanismos de defesa, passa a atribuir um novo sentido à adversidade vivenciada, pois, ao enfrentá-la, consegue reconfigurar o significado da situação (Barlach \& Malvezzi, 2010).

Contudo, para falar em reconfiguração do significado de uma situação adversa, é preciso compreender que as pessoas, em um processo de enfrentamento, realizam re-exames cognitivos sobre o fato vivenciado. Isto é, tais re-exames são os processos pelos quais as pessoas refletem sobre o dano ou ameaça proveniente do contexto ao qual elas estão inseridas. Tais processos de reflexão fazem com que os re-exames cognitivos também se direcionem ao desenvolvimento de mecanismos de defesa para lidar com a situação vivenciada, de modo que tais mecanismos atuarão na reconfiguração do acontecido, ou mesmo para o desenvolvimento da tolerância frente a uma determinada adversidade (Tavares et al., 2001 ).

Embora haja a compreensão de que o processo de enfrentamento a uma situação adversa decorra da combinação de fatores de proteção internos e externos da pessoa, uma vez transformados em mecanismos de defesa, a literatura disponível sobre este fenômeno ainda não apresenta um escopo teórico que indique 
um padrão dominante do processo de enfrentamento em si, realizado pelas pessoas perante a determinada situação hostil. Mas sugerem Lazarus e Folkman (1984), clássicos autores do conceito de fatores de proteção, que um bom parâmetro a ser empregado para identificar a existência de possíveis padrões de enfrentamento é delimitar, nas pesquisas sobre o fenômeno, o foco de estudo nos "tipos de pessoas, para determinados tipos de estresse psicológico, em determinados momentos e sob condições conhecidas" (Lazarus \& Folkman, 1984, p. 147). Ou seja, formar a base de participantes do estudo a partir das similaridades de condições e situações por eles vivenciadas, o que é caso nesta pesquisa.

Uma vez estabelecida a base de participantes de pesquisa, respeitados os critérios igualitários de sua formação, para que seja possível parametrizar a relação entre padrões de enfrentamentos, isto é, parametrizar o processo de transformação dos fatores de proteção em mecanismos de defesa, Lazarus e Folkman (1984) sugerem ainda o uso do conceito de fases do enfrentamento. Para os autores, uma pessoa realiza um processo de enfrentamento a uma situação adversa por meio de três fases, a saber: fase de antecipação; fase de impacto; e a fase de pós-confrontação; que serão detalhadas a seguir.

A fase de antecipação corresponde ao momento em que um evento de abrupta mudança ainda não ocorreu, mas a pessoa, já imbuída de um sentimento de ameaça pela possibilidade de ocorrência do evento, inicia um processo de questionamento sobre quais serão as possíveis consequências para ela se, de fato, o mesmo ocorrer. Essa fase é permeada por questionamentos como: "pode ser evitado? de que forma? o que pode ser feito de maneira preparatória para minimizar ou evitar os danos? alguns danos podem ser evitados enquanto outros danos devem ser resistidos?" (Lazarus \& Folkman, 1984, p. 147). Nesta pesquisa, para abranger a experiência dos entrevistados na fase de antecipação à operação de aquisição da instituição financeira internacional em que trabalhavam, utilizamos a seguinte pergunta: "Como você se sentiu diante da notícia de venda do banco, principalmente em relação ao seu emprego?".

Na fase de impacto muitas das reflexões e ações planejadas pela pessoa, em sua fase de antecipação ao evento de abrupta mudança, deixam de ser relevantes. A pessoa percebe que a maneira como a situação de mudança se coloca pode ser além ou aquém do que previamente se havia tentado prever (Lazarus \& Folkman, 1984). Isto quer dizer que na fase de impacto a pessoa faz um reexame cognitivo sobre o evento ocorrido, para que ela consiga compreender com precisão os significados da situação adversa que acaba por vivenciar (Silva, 2010). Mas compreender com precisão uma situação adversa não é um processo simples, tampouco rápido. A percepção de precisão sobre uma determinada circunstância decorre da reavaliação que a pessoa realiza sobre o evento ocorrido, e este processo requer uma "energia mental tão focada em agir e reagir que pode levar um tempo considerável para esclarecer o que aconteceu ou avaliar seu significado" (Lazarus \& Folkman, 1984, p. 148). Assim, como tentativa de apreender a experiência dos entrevistados na fase de impacto à operação de aquisição, nesta pesquisa utilizamos a seguinte questão: "O que você fez para lidar com a situação gerada no momento em que a venda do banco, de fato, se consolidou?".

Já a fase de pós-confrontação é o momento do processo de transformação dos fatores de proteção em mecanismos de defesa no qual a pessoa, em conhecimento sobre como se deu seu processo de enfrentamento à situação adversa, inicia uma série de considerações sobre o fato ocorrido. Tais considerações emergem de questionamentos que a pessoa faz a si mesma, dentre os quais: "qual foi o significado pessoal ou a importância do que aconteceu? que novas exigências, ameaças e desafios a situação impõe? pode tudo voltar ao que era ou as coisas mudaram significativamente?" (Lazarus \& Folkman, 1984, p. 148). Para compreender a experiência dos entrevistados na fase de pós-confrontação à operação de aquisição da instituição financeira internacional em que trabalhavam, nesta pesquisa fizemos uso da seguinte pergunta: “O que representou para você ter vivenciado essa situação de venda do banco?".

Partimos do entendimento de que uma pessoa, após vivenciar um evento de abrupta mudança, tem alterada sua relação com o seu ambiente, pois, tal como afirmam Barlach e Malvezzi (2010), a situação adversa faz emergir um novo contexto a ser vivenciado. Assim, ao buscarmos compreender o que representou a experiência dos entrevistados em seu processo de enfrentamento à operação de aquisição a fase de pós-confrontação - procurou-se identificar como elas conseguiram reequilibrar suas emoções, ajustando e flexibilizando, assim, suas ações e comportamento para lidar com o novo contexto que se faz posto em suas relações no novo ambiente de trabalho.

O enfoque específico em compreender o processo de enfrentamento realizado pelas pessoas frente às situações adversas geradas pelas transformações no ambiente de trabalho conflui para o escopo de 
interesse desta pesquisa. Silva (2010) afirma que um processo de enfrentamento às situações adversas em contexto organizacional ocorre da seguinte maneira: ao emergirem sentimentos que causam desequilíbrio emocional nas pessoas, elas mobilizam e combinam fatores de proteção internos e externos. Após esta combinação, as pessoas atribuem utilidade aos seus fatores de proteção transformando-os em estratégias de enfrentamento, ou seja, mecanismos de defesa que, ao serem utilizados, criam maneiras alternativas de lidar com a situação, de modo que as pessoas passam a atribuir um novo sentido à situação adversa, já que, ao enfrentá-la, reconfiguraram o seu significado.

Compreendendo qual o propósito e como se dá o processo de enfrentamento realizado pelas pessoas frente às situações adversas no ambiente de trabalho, ressaltamos que, para esta pesquisa, utilizamos o conceito de fases de enfrentamento de Lazarus e Folkman (1984) como critério para interpretação dos dados empíricos deste trabalho, ou seja, os relatos dos funcionários que vivenciaram a operação de aquisição da instituição financeira internacional que trabalhavam, por outra instituição nacional. Esta escolha se deu pela tentativa de parametrizar como ocorreu o processo de transformação do elemento formação acadêmica em uma estratégia de enfrentamento, realizado pelos entrevistados, para lidar com os impactos gerados no ambiente de trabalho. Para tanto, escolhemos os trechos dos depoimentos coletados onde foi possível apreender, de modo explícito, a utilização deste elemento como um fator de proteção pelos entrevistados - fosse para lidar com a fase de antecipação, impacto ou pós-confrontação à operação de aquisição.

Os resultados obtidos por meio do critério de fases de enfrentamento serão apresentados mais adiante, especificamente na seção 5 ("Apresentação e Interpretação dos Dados Coletados"). Isto porque, como o propósito desta pesquisa é compreender não só como o elemento formação acadêmica pode ser transformado em uma estratégia de enfrentamento para lidar com as abruptas mudanças no ambiente de trabalho, mas também como neste processo a pessoa ganha condições de ressignificar o sentido da própria vida profissional, entendemos ser relevante delinear preliminarmente uma noção contemporânea de carreira, para que, assim, possamos abranger o entendimento acerca das principais transformações que vêm impactando a concepção de vida profissional em tempos atuais. Assim, este aporte teórico é o conteúdo apresentado a seguir.

\section{Noção Contemporânea de Carreira}

O construto carreira e os conceitos a ele relacionados passaram por significativas alterações ao longo das últimas décadas, de modo que autores como Greenhaus e Callanan (1994), Chanlat (1995), Martins (2001) e Hall (2002) destacam que a temática pode ser compreendida a partir de duas abordagens: a tradicional e a moderna ou contemporânea.

Chanlat (1995) e Tavares, Pimenta e Balassiano (2007) explicam a abordagem tradicional a partir de sua principal característica: a suposição de que as organizações responsabilizam-se pelo desenvolvimento de carreira de seus empregados. Greenhaus e Callanan (1994) e Hall (2002) acrescentam que, nesta perspectiva, a carreira é tratada como uma profissão ou como uma progressão linear vertical no interior de uma organização, sendo a estabilidade no vínculo e no tempo algumas de suas grandes marcas. A principal medida de sucesso neste modelo, conforme Ribeiro, Trevisan e Guedes (2009), é o degrau hierárquico atingido pelo indivíduo dentro da organização. Para ilustrar esse modelo de desenvolvimento de carreira, Evans (1996) utiliza a metáfora da "carreira como uma escada", quando uma pessoa, ao entrar no mercado de trabalho, busca uma escada e, ao encontrá-la, vai subindo cada degrau, assumindo níveis mais altos de responsabilidade, de status ou de salário.

Este modelo tradicional de carreira, como explica Chanlat (1995), predominou até meados da década de 1970. A partir daí, Greenhaus e Callanan (1994), Chanlat (1995) e Evans (1996) destacam que as mudanças sociais, econômicas, culturais e políticas conduziram a uma nova concepção de carreira que, segundo Chanlat (1995), é marcada pela instabilidade, descontinuidade e horizontalidade. Nesta perspectiva contemporânea, London e Stumpf (1982) definem carreira como a sequência de posições ocupadas e de trabalhos realizados durante a vida de uma pessoa, envolvendo uma série de estágios e a ocorrência de transições que refletem necessidades, motivos, aspirações individuais, expectativas e imposições da organização e da sociedade. Similarmente, Hall (2002) define carreira como a sequência individualmente percebida de atitudes e comportamentos associados às experiências e atividades relacionadas ao trabalho realizado ao longo da vida de uma pessoa. Diante desta nova abordagem e da 
ampla diversidade de opções profissionais abrigadas neste novo conceito, expandiu-se a definição de carreira, de modo que a mesma pode significar, ao mesmo tempo:

emprego assalariado ou atividade não remunerada; pertencimento a um grupo profissional (sindicalizado ou não) ou a manifestação da mais pura idiossincrasia (a carreira de um artista); vocação (algo que alguém faz com alto nível de comprometimento afetivo) ou ocupação (algo que alguém faz por necessidade ou obrigação); posição em uma organização (associada a passagens por diversos cargos na hierarquia institucional) ou trajetória de um indivíduo que trabalha por conta própria; uma fonte de informação para as empresas alocarem recursos (humanos) ou então um roteiro pessoal para a realização dos próprios desejos (Bendassolli, 2009, p. 388).

Outras noções emergiram e se popularizaram por abrigarem-se sob o modelo contemporâneo de carreira. Hall (1996), por exemplo, desenvolveu o conceito de carreira proteana, compreendida como uma série de experiências e de aprendizados pessoais, relacionados ao trabalho ao longo da vida. O termo proteano provém da mitologia grega na qual o deus Proteus possuía habilidade de mudar de forma de acordo com sua vontade e circunstância. Esta característica é metaforicamente associada ao perfil do profissional contemporâneo quanto à habilidade de gerenciar a sua própria carreira. Conceito similar foi desenvolvido por Arthur e Rousseau (2001), quando os mesmos definiram as carreiras sem fronteiras, que se opõem aos tipos tradicionais, por sugerirem a independência do indivíduo em relação a uma organização, a possibilidade da carreira ser negociada fora do atual empregador, o fato de que as pessoas tornam-se responsáveis por suas carreiras futuras por meio do cultivo de networks e pela busca constante de conhecimento, sem levar em consideração obstáculos estruturais e a possibilidade da carreira ser planejada ou alterada em função de razões pessoais ou familiares. Da mesma maneira, as carreiras inteligentes, definidas por Arthur, Claman e DeFillippi (1995), propõem que as pessoas acumulem competências semelhantes às das organizações, sem a subordinação a um vínculo empregatício. Assim, as pessoas devem, primeiramente, conhecer os motivos de seu engajamento profissional, sua identidade, motivações, necessidades e identificação com o trabalho (knowing why). A segunda competência representa as habilidades e especialidades individuais relevantes para o trabalho (knowing-how). Por fim, a competência knowing-whom refere-se às relações interpessoais e networks importantes para o trabalho.

Embora adotando diferentes denominações tais como carreira proteana (Hall, 1996; 2002; Arthur, Hall \& Lawrence, 1989), sem fronteiras (Arthur \& Rousseau, 2001) ou inteligente (Arthur \& Claman; Defillippi, 1995), emerge, nestas novas abordagens acerca do tema, a responsabilidade do indivíduo no gerenciamento de sua carreira (Hall, 1996), aliada à independência deste em relação a uma organização (Arthur \& Rousseau, 2001). Dessa forma, Milkovich e Boudreau (2000) destacam que a carreira passa a incluir o trabalho em diversas organizações, em diferentes ocupações e passa a depender cada vez mais da capacidade do indivíduo de criar o seu caminho no decorrer da vida laboral do que das alternativas proporcionadas por uma única organização.

Retornando à metáfora proposta por Evans (1996), as carreiras passam a ser interpretadas a partir de uma "natureza espiral", em ziguezague, e não de escadas, na qual as pessoas não se vêem apenas com uma única carreira, mas sim com duas ou mais, durante o curso de suas vidas. Assim, o que se vê atualmente, como explicam Harrington e Hall (2007), é que as carreiras não se fecham em estágios ao longo do tempo, mas tornam-se flexíveis, adaptando-se a novos começos e mudanças, passando a ser vistas como uma série de ciclos de aprendizado ao longo da vida de uma pessoa. Neste sentido, Chanlat (1995) ressalta que as carreiras passam a ser menos estáveis e lineares do que antes, pois como explicam Veloso, Dutra e Nakata (2008), a carreira passa a ser tratada como uma série de estágios e transições que variam de acordo com pressões originadas no próprio indivíduo e no ambiente, e não a partir da suposição de que a carreira seja linear, de modo que é possível identificar a incidência de movimento, tanto para o indivíduo quanto para a organização.

Sendo as pessoas as principais responsáveis pelo desenvolvimento de suas carreiras, Ihes são exigidos novos comportamentos, competências e posturas que, por serem valorizadas no mercado de trabalho, independentemente da carreira adotada, passam a fazer parte do perfil deste trabalhador contemporâneo. Dentre essas características, Bridges (1995) aponta a mentalidade de fornecedor e a empregabilidade.

A mentalidade de fornecedor, segundo Bridges (1995), refere-se à percepção do trabalhador como uma unidade econômica autônoma, capaz de oferecer seus serviços e administrar sua carreira como se fosse uma empresa. A empregabilidade caracteriza-se como "a condição de ser empregável, isto é, de dar ou conseguir emprego para os seus conhecimentos, habilidades e atitudes intencionalmente desenvolvidos 
por meio de educação e treinamento sintonizados com as novas necessidades do mercado de trabalho" (Minarelli, 1995, p. 11). Ambas as características, conforme Bridges (1995), representam certo "eu empreendedor", que se torna um atributo fundamental do indivíduo empregável, que precisa autogerir sua carreira e ver a si mesmo como se fosse uma empresa, um negócio.

Constata-se, portanto, que o discurso acerca da noção de carreira evoluiu de abordagem tradicional, quando a organização assumia a responsabilidade de gerenciar as carreiras de seus empregados, à noção de autogerenciamento de carreira, presente na concepção contemporânea, onde a carreira é mais flexível e instável, passa a ser responsabilidade do indivíduo e está relacionada às diversas atividades profissionais por ele desempenhadas ao longo de sua vida. Exige-se do profissional uma busca permanente da capacitação e do aprendizado contínuo, independente de quem os financia. Além disso, fica evidente que a dedicação a uma organização é apenas uma opção e não mais a única, sugerindo as mais diversas possibilidades em termos de trajetória e desenvolvimento de carreira (Duarte, 2010).

Apresentado o aporte teórico utilizado para sustentação do argumento do artigo em pauta, delineamos a seguir os procedimentos metodológicos adotados para a realização desta pesquisa.

\section{Procedimentos Metodológicos}

Para apresentar os procedimentos adotados para realização da pesquisa em pauta, é importante frisar que os dados empíricos utilizados neste artigo foram originalmente coletados para atingir o objetivo de compreender o processo de transformação dos fatores de proteção em mecanismos de defesa, realizado pelos funcionários que vivenciaram, em 2006, a operação de aquisição da instituição financeira em que trabalhavam, por outra nacional, a fim de enfrentarem esta situação adversa e permanecerem trabalhando na instituição adquirente. Mas, como tende a ocorrer em pesquisas de natureza qualitativa cujo foco está na interpretação das minúcias dos dados, alguns aspectos inusitados surgiram dos dados coletados durante o processo de interpretação, dentre os quais a questão da formação acadêmica, que emergiu como um fator de proteção utilizado por parte dos funcionários como uma estratégia de enfrentamento.

Considerando que, se este aspecto inusitado fosse interpretado à luz de outros preceitos teóricos, surgiriam discussões interessantes para o entendimento desse fenômeno organizacional, procedeu-se o estímulo para realização deste artigo. Para fins deste trabalho foram utilizados os relatos de funcionários através dos quais foi possível apreender, de maneira explícita, o elemento formação acadêmica como uma estratégia de enfrentamento, frente à abrupta mudança vivenciada por eles no ambiente de trabalho.

Em virtude do fenômeno estudado e do objetivo pretendido neste artigo, foi preservado o delineamento metodológico adotado na realização da pesquisa preliminar, da qual os dados empíricos são oriundos. Sendo assim, esta pesquisa é de natureza qualitativa, pois se buscou ouvir dos funcionários que presenciaram, em 2006, a operação de aquisição da instituição financeira internacional em que trabalhavam, as suas vivências e percepções em relação àquele momento, quando se viram diante da necessidade de readequarem seus comportamentos e ações em relação às suas vidas profissionais. Por este delineamento de pesquisa, buscou-se preservar a riqueza e expressividade das experiências dos entrevistados, para que assim fosse possível se aproximar da compreensão do fenômeno em estudo.

É uma pesquisa descritiva por expor ou definir um assunto, apresentando as características do mesmo ou de determinado fenômeno, como por exemplo, o perfil de um grupo de pessoas (Cooper \& Schindler, 2003). Quando uma pesquisa é de natureza qualitativa e descritiva, seu foco está na interpretação (Moreira, 2004). As descrições de um fenômeno balizam o pesquisador a perceber e interpretar os sentidos que uma pessoa atribuiu à sua ação ao vivenciar o fenômeno, o que o ajuda a compreender os sentidos e significados que as pessoas atribuíram ao fenômeno vivenciado, como é o caso neste artigo.

Quanto ao corte temporal, a pesquisa é seccional com perspectiva longitudinal. Para Vieira (2004) embora neste corte de pesquisa a coleta de dados seja realizada em um único momento, o pesquisador precisa resgatar informações de períodos anteriores, pois o foco está no fenômeno e na forma como se caracteriza no momento da coleta, e os dados resgatados do passado são, normalmente, utilizados para explicar a configuração atual do fenômeno. Neste estudo, os dados foram coletados em 2010, mas foram resgatados fatos ocorridos em 2006.

A escolha dos participantes da pesquisa foi realizada de maneira intencional e não aleatória, sendo determinada por três critérios, que foram, impreterivelmente, atendidos em sua totalidade: 1) funcionários que trabalhavam na instituição financeira adquirida (aqui, nesta pesquisa denominada de Banco I, por se 
tratar de uma instituição internacional); 2) que vivenciaram a operação de aquisição, no ano de 2006; e 3) que ainda exercessem suas atividades de trabalho na instituição adquirente (aqui, denominada de Banco N, por se tratar de uma instituição nacional, e não termos a permissão para mencionar o seu nome neste artigo).

A coleta dos dados primários foi realizada por meio de entrevistas semiestruturadas, que, conforme Triviños (2007), valorizam tanto a presença do investigador como oferecem perspectivas possíveis para que o informante alcance a liberdade e a espontaneidade necessárias para relatar fatos de sua vida, enriquecendo, assim, a investigação. Nesta pesquisa, para que as perguntas fossem respondidas da maneira mais espontânea possível e, por conseguinte, permitissem uma compreensão aprofundada do fenômeno investigado, foi garantido aos funcionários o seu anonimato. Em face do compromisso de não tornar explícita a menção de seus nomes, os seis participantes da pesquisa, por serem todos bancários, foram denominados ao longo da transcrição de seus depoimentos de B1, B2, B3, B4, B5 e B6. Além do anonimato, a fim de se evitar quaisquer tipos de intimidação ou inibição no relato dos fatos de suas vidas, a coleta dos depoimentos foi realizada por meio de pesquisa de campo realizada em locais escolhidos de acordo com a preferência e interesse de cada um dos participantes.

Há de se ressaltar que na pesquisa preliminar, de onde os dados empíricos são oriundos, a validade interna quanto à composição amostral dos participantes de pesquisa foi assegurada pela utilização da técnica de snow bal/ (Appolinário, 2006). Isto quer dizer que foi aplicado o critério de exaustão na coleta de dados. Ou seja, no momento em que as informações oriundas do conjunto das entrevistas realizadas passaram a se repetir, foi finalizada a coleta de dados, sendo, portanto, a aplicação do critério de exaustão que estabeleceu a quantidade de seis funcionários que formaram a amostra da população utilizada na pesquisa. Ressalta-se este aspecto, pois, para este artigo, foi delimitada a utilização apenas os relatos de funcionários em que foi possível apreender, de maneira explícita, o elemento formação acadêmica como uma estratégia de enfrentamento, utilizada frente à operação de aquisição, que foram: B2, B3, e B6. Isto indica que a composição amostral, da qual faz uso este trabalho, não fora formada diretamente por meio da técnica de snow ball. Mas leva-se em consideração que é em face da delimitação de pesquisa assumida para realização deste artigo, quanto à sua composição amostral. Isto justifica a não utilização dos depoimentos de B1, B4, e B5, já que nos relatos destes funcionários, não foram identificadas menções explícitas ao elemento formação acadêmica, como estratégia de enfrentamento para lidar com a operação de aquisição.

O tratamento dos dados foi iniciado com a transcrição das entrevistas - gravadas por meio de dispositivo eletrônico que dispõe de recurso de áudio. Para interpretar os dados coletados, foi utilizada a técnica de análise de conteúdo (Minayo, 2001). A aplicação desta técnica se deu, primeiramente, pela definição da unidade de registro utilizada para a interpretação dos conteúdos dos discursos dos entrevistados que, para este estudo, optou-se pela unidade de frase. Já a unidade de contexto foi estabelecida pela conjuntura da qual o trecho da mensagem investigada era parte integrante. Para tanto, utilizaram-se como parâmetro as categorias de análise estabelecidas a partir do conceito de fases de enfrentamento (Lazarus \& Folkman, 1984) apresentado na fundamentação teórica desta pesquisa, a saber: fase antecipação; fase de impacto; e fase de pós-confrontação.

A partir de então, foi realizada a pré-análise dos dados coletados, isto é, a organização do material de pesquisa de acordo com as categorias de análise previamente estabelecidas. Posteriormente, foram selecionados os trechos significativos das mensagens que, nesta pesquisa, referem-se aos relatos dos depoimentos que constavam, explicitamente, o elemento formação acadêmica. Em seguida foi realizada a descrição analítica do material: foram agrupados os relatos em que contavam a menção ao elemento formação acadêmica como uma estratégia de enfrentamento, por respectiva categoria analítica. Ou seja, os relatos foram agrupados de acordo com a fase na qual os funcionários lançaram mão da formação acadêmica como uma estratégia de enfrentamento para lidar com os impactos gerados pela operação de aquisição.

A partir da descrição analítica dos dados, e orientando-se pelo aporte teórico deste estudo, foi iniciado o processo de interpretação dos conteúdos das mensagens selecionadas. Buscou-se, nesse momento, sintetizar as coincidências e divergências nas mensagens provenientes dos discursos dos participantes de pesquisa. Por fim, realizou-se o tratamento dos dados, de modo que se buscou desvelar os conteúdos subjacentes dos depoimentos coletados, em face do que foi manifestado nas mensagens decorrentes das narrativas dos entrevistados. Assim, por meio da aplicação da técnica de análise de conteúdo, foi possível, no decorrer do processo de interpretação das narrativas coletadas, enfatizar os conteúdos subjacentes das 
mensagens implícitas e explícitas das falas dos participantes da pesquisa, resultados estes, apresentados na próxima seção.

\title{
5 Apresentação e Interpretação dos Dados Coletados
}

Primeiramente, com o intuito de compreender as reações iniciais das pessoas diante da venda do Banco I para o Banco $\mathrm{N}$, Ihes foi questionado como estas se sentiram diante deste fato, principalmente em relação ao seu emprego. Seguem alguns relatos:

\begin{abstract}
B2: “Eu tive receio de perder o meu emprego. Isso (o receio) eu tinha, tinha sim. Não só eu, como todo mundo tinha (os colegas de trabalho do Banco /)... mesmo eu já estando no Banco I há dois anos (no momento da venda do Banco /)".

B3: “Ah, eu acho que todo mundo sente um pouquinho né? Se falar que não, é mentira! Você fica naquela espera pra saber o que vai acontecer. Na verdade, em uma operação como essa (venda do banco) você não sabe qual é a 'teoria', qual a (pausa) cultura do banco que vai prevalecer. Então assim, se prevalecer a cultura deles (banco adquirente) como que vai ser a sua área? Será que eles (o banco adquirente) vão ter a sua função? Vai ter cortes (demissões)? Não vai ter cortes (demissões)?... Eu acho que todo mundo pensa um pouco nisso (em tais questões)"
\end{abstract}

Neste início de novo ciclo de carreira, emergiu em B2 e B3 o sentimento de medo diante do gatilho que potencialmente desencadearia profundas transformações sem suas vidas profissionais. Em B3 ainda emergiu a expectativa de saber o que estaria por acontecer em seu ambiente de trabalho. No relato de B3 fica clara a preocupação com o futuro profissional, principalmente em relação à adaptação às novas funções ou até mesmo uma possível demissão. As reações apresentadas pelos funcionários provêm, tal como aponta Tavares et. al (2001), do reexame cognitivo por eles realizados frente à situação de mudança, já que as consequências da operação de aquisição, por ainda serem desconhecidas aos funcionários, Ihes criou certo desequilíbrio emocional, como asseveram Cowan, Cowan \& Schulz (1996).

O bancário B6, por outro lado, apresentou uma postura inusitada, demonstrando mais segurança e certa ausência de receio diante do processo de aquisição:

B6: "É... (pensativo) ao mesmo tempo em que eles (o Banco I) nos informaram sobre a venda do Banco I, eles (o Banco \) nos tranquilizaram quanto a isso aí (não haveria demissões)... porque com a venda viriam novos valores (organizacionais/profissionais) e não o contrário. Ou seja, o Banco $\mathrm{N}$ não iria perder os valores (organizacionais/profissionais) já conquistados (pelo Banco )"

Percebe-se que, conforme o depoimento de B6, este atingiu certa tranquilidade frente à situação, posto que Ihe foi informado que não haveria demissões. Assim, ao ter existido a necessidade de tranquilizá-lo, compreende-se que, possivelmente em B6 emergiu o sentimento de medo de perder o emprego frente à notícia de venda do Banco I.

Assim, mudanças contextuais podem ser compreendidas como gatilhos capazes de despertar o repensar da carreira, o que pode dar início de um novo ciclo, já que a noção contemporânea de carreira, conforme London e Stumpf (1982) e Harrington e Hall (2007), reflete as mudanças e transições originadas no próprio indivíduo como no ambiente e/ou contexto no qual ele está inserido. Os relatos apresentados por B2, B3, e B6 deixam claro que há uma expectativa de mudanças no ambiente de trabalho e que os mesmos encontram-se preocupados com isto, demonstrando a consciência que aquele processo de mudança os impactará de alguma forma.

Tendo conhecimento da forma como os entrevistados se sentiram em relação aos seus empregos diante da notícia da operação de aquisição, Ihes foi indagado: "O que você fez para lidar com a situação gerada no momento em que a venda do Banco I para o Banco N, de fato, se consolidou?" A questão foi realizada com o intuito de compreender as ações empreendidas pelos bancários para lidar com aquela situação de mudança organizacional, ou seja, se estes teriam novos objetivos em relação à vida profissional, e como buscariam concretizá-los. Tais ações corresponderiam à fase inicial de um novo ciclo de carreira, conforme Greenhaus e Callanan (1994) e Harrington e Hall (2007). Os seguintes relatos foram obtidos:

B2: “A primeira reação foi a de saber que o Banco $\mathrm{N}$ não tinha o cargo que eu exercia no Banco I. Então eu falei 'Tenho que fazer alguma coisa pra mudar!'. Eu continuei fazendo o meu (atividades de trabalho) e... eu fui me especializar (curso de pós-graduação) e tirar a ANBID, que é o certificado CPA-10 do mercado financeiro. Eu queria atingir mais algumas 'coisas' (objetivos pessoais) lá dentro... (do Banco $\mathrm{N}$ com a profissão de bancário) 
Trabalhando eu atinjo o que eu quero sabe? [ ...] então foi mais eu mesmo... iniciativa minha mesmo... 'Quero?' 'Não quero?'... e vamos lá (prosseguir trabalhando no banco)".

B3: “Ah eu encarei!... (a situação de venda do Banco 1) Eu fui estudar o que o Banco N queria... e continuei trabalhando, porque independente do banco, eles (os bancos) sempre vão querer resultados e... banco quer isso, quer que você trabalhe... Foi mais assim... aprender questão de sistemas (sistemas de gestão do Banco $\mathrm{N}$ ), coisas operacionais assim. E também... (pausa) eu não parei de estudar. Os meus estudos continuam na verdade... Eu já tinha uma faculdade de economia... e agora faço direito (curso de graduação)... Minha família também é bem tranquila, então foi tudo bem em relação a essa situação (novo ambiente de trabalho)".

Nos relatos de B2 e B3 ficou evidenciado como tais bancários compreenderam a situação como uma oportunidade de recomeço, de traçar novos objetivos profissionais e planos e metas para concretizá-los. Essa percepção fez com que B2 percebesse a necessidade de fazer algo, isto é, encontrar alguma maneira ou alternativa para lidar com as novas situações geradas no ambiente de trabalho do Banco $\mathrm{N}$. Neste processo, o bancário traçou novos objetivos de carreira, os quais ele admite que poderiam ser atingidos na própria instituição, mas para que isso ocorresse, algumas ações seriam necessárias, tais como sua especialização e a certificação ANBID - CPA-10.

B3 relata que, além de se adaptar aos novos procedimentos exigidos pelo Banco $\mathrm{N}$, não se acomodou à situação vivida naquele momento e buscou um novo curso de graduação, demonstrando que tinha consciência acerca da instabilidade de sua carreira naquele momento. Neste caso, o curso de graduação em direito seria um meio pelo qual o bancário poderia atingir possíveis novas metas de carreira.

$\mathrm{Na}$ perspectiva de B2, aquele momento foi interpretado como um desafio que the proporcionou oportunidades de aprendizado e desenvolvimento profissional: "Foi um desafio! Foi um desafio! Mas a gente fica com medo do que pode acontecer [ ...] Você tem que aprender e mostrar que sabe, pra ter um diferencial no banco sabe?" No entanto, o bancário não considera que esta tenha sido uma mudança significativa, embora reconheça que o momento desencadeou nele certas dúvidas em relação ao que aconteceria com seu trabalho após a venda do Banco I.

Percebe-se que os funcionários tiveram de lidar com as novas circunstâncias provenientes da operação de aquisição. Isto evidencia a concepção de fase de impacto abordado por Lazarus \& Folkman (1984), uma vez que nos relatos dos funcionários são deflagrados os impactos sentidos por eles com a consolidação da venda do Banco I e, por conseguinte, quais artifícios foram por eles lançados mão para lidar com essa abrupta mudança no ambiente de trabalho.

Conforme o relato a seguir, B6 demonstra segurança em face do momento de transição, principalmente por acreditar no seu preparo e experiência profissional e por ter recebido o apoio da família:

B6: “Minha família... total apoio, sempre 100\%! É... (pensativo) de carreira acadêmica eu não me preocupei, até mesmo porque eu tenho formação em bacharel em administração de empresas e tenho também uma especialização (retoma rapidamente). E no meio dessa situação toda da venda do Banco l, a gente (no caso ele próprio) acaba tendo a informação de que nem todos os colegas (de trabalho) têm uma especialização... vamos dizer assim. Então, eu fiquei tranquilo desse lado meu acadêmico e de formação".

Assim, segundo o relato acima, o bancário parece não ter considerado a situação como propícia à elaboração de novos objetivos profissionais e de planos para atingí-los, pois já se considerava bem mais preparado profissionalmente em relação aos colegas, o que o colocaria numa posição confortável diante de reestruturações, demissões ou quaisquer outras mudanças decorrentes do processo de aquisição. Nota-se que B6 realizou o processo de reconfiguração do significado da situação, como declaram Barlach \& Malvezzi (2010), já que o funcionário, embora tenha se defrontado com uma abrupta mudança no ambiente de trabalho, conseguiu atribuir um sentido positivo à situação por se considerar preparado para enfrentá-la.

Contudo, ainda para B6, este momento não se mostrou propício ao repensar sua vida profissional, visto que o mesmo não traçou novos objetivos de carreira ou quaisquer planos para atingi-los. Embora este bancário tivesse compreendido que a situação Ihe exigia uma mudança de postura, comportamento e ações, este pareceu, no momento do processo de aquisição, considerar-se estabilizado em relação à sua vida profissional, demonstrando uma compreensão de carreira mais alinhada à abordagem tradicional, baseada na progressão linear vertical no interior de uma organização, como explicam Greenhaus e Callanan (1994) e Hall (2002). 
A fim de compreender quais significados os funcionários atribuíram à experiência de enfrentar a abrupta mudança no ambiente de trabalho, a eles foi indagado: "O que representou para você ter vivenciado essa situação de venda do Banco I para o Banco N?" Os seguintes relatos foram coletados:

B3: “A gente aprende né? A partir do momento que você está trabalhando, independente da área, você está aprendendo cada dia mais! Principalmente devido à venda do Banco I, eu passei para um banco (Banco $M$ que é líder de mercado, e isso é diferente entendeu?! A organização em si, é diferente. A forma de administrar o banco ( $B a n c o ~ M$ é muito boa. O Banco $\mathrm{N}$ é bom nisso!"

Nos trechos dos depoimentos de B3, identifica-se o sentimento de aprendizado. Ou seja, para B3 a experiência de passar pela operação de aquisição do Banco I, Ihe possibilitou conhecer os processos de gestão do Banco $\mathrm{N}$, sendo estes possivelmente processos que the possibilitaram ampliar sua gama de conhecimento frente aos quais estava acostumado a executar/lidar no Banco I.

B2: “Eu acho assim... (gesticula) até hoje ainda tem bastante coisa que o pessoal diz que vai mudar (no Banco $M$. Mas hoje em dia, não importa pra mim se vai mudar ou não! Porque você tem que fazer o seu (atividades de trabalho) e... tentar fazer bem. O que vai acontecer, vai 'ditar' o trabalho que tem que ser feito... Hoje em dia eu já me sinto bem no Banco N. Pode tudo mudar, mas hoje eu já estou mais tranquilo".

B6: “Ah... crescimento pessoal, profissional, controle emocional... Isso agregou, de fato, porque uma coisa (a venda do Banco /) que a gente (o funcionários do Banco ) achou que ia ser tão difícil... Aí você vê hoje já tudo conquistado e levando de uma maneira corriqueira... Acaba que as informações vão chegando e você vai se adaptando".

Em B2 e B6 emergiram distintos significados da experiência obtida com a venda do Banco I. No relato de B2 observa-se que ele desenvolveu a capacidade de ser destemido quanto às situações de mudanças de sua vida, principalmente no contexto profissional. Já no relato de B6 observa-se o significado de crescimento pessoal, profissional e controle emocional, obtidos por meio da experiência do entrevistado ao passar pela situação de venda do Banco I. Observa-se, também, que a notícia de venda do Banco I foi para B6 mais impactante do que o processo de consolidação desta operação em si.

Vale destacar que a capacidade de aprendizado foi um recurso lançado mão por todos os participantes da pesquisa, mesmo que em níveis diferentes. Ou seja, a capacidade de aprender dos entrevistados foi uma estratégia de enfrentamento que Ihes proporcionou condições para lidar com os impactos negativos vivenciados no ambiente de trabalho. Isto indica que todos os entrevistados demonstraram esforços em seus comportamentos para mobilizarem fatores internos e externos frente à situação, tal como afirmam Lazarus \& Folkman (1984) quanto à mobilização de fatores de coping e buffers realizada pela pessoa, para enfrentar as situações hostis da vida.

Em relação aos fatores de proteção internos (coping), foram identificados: ambição; autoconfiança; autoconhecimento; capacidade de aprendizado; iniciativa; permanecer realizando atividades de trabalho; e trabalhar sob pressão. E os fatores de proteção externos (buffers) foram: curso de especialização; certificação da ANBID; cursar outra graduação; estar empregado; família; formação acadêmica; formação acadêmica dos colegas de trabalho; e, notícia de seguridade do emprego.

A partir de então, todos os funcionários passaram a atribuir novos significados à situação ao fazerem uso de seus fatores de proteção por meio de estratégias de enfrentamento, ou seja, quando eles transformaram seus fatores de proteção em estratégias de enfrentamento. Como exemplo, para B6, a formação acadêmica dos colegas de trabalho emergiu para ele como um fator de proteção externo, cuja utilidade, isto é, a estratégia de enfrentamento desenvolvida, foi utilizar essa informação como um critério de distinção profissional entre os demais funcionários que igualmente se defrontram com a operação de aquisição.

Assim, compreendeu-se que o processo de enfrentamento realizado pelos funcionários frente às situações adversas, geradas pela venda do Banco I para o Banco N, ocorreu da seguinte maneira: ao emergirem sentimentos que Ihes causaram um desequilíbrio emocional, ao se defrontarem com a situação adversa, eles mobilizaram e combinaram fatores de proteção internos e externos, dentre os quais, a formação acadêmica. Em seguida, atribuíram utilidades a esse fator de proteção, transformando-o, assim, em distintas estratégias de enfrentamento, ou seja, mecanismos de defesa. Isto Ihes deu condições de lidarem de maneiras alternativas com a mudança no ambiente de trabalho, de modo que, ao lançarem mão de suas estratégias de enfrentamento, os funcionários conseguiram enfrentar a situação adversa, reconfigurando, assim, o significado da operação de aquisição e da própria carreira. 


\section{Conclusões}

Por esta pesquisa buscou-se compreender de que forma o elemento formação acadêmica auxiliou os funcionários que vivenciaram, no ano de 2006, a operação de aquisição de uma instituição financeira internacional em que trabalhavam, por outra instituição nacional, a lidarem com os impactos dessa abrupta mudança no ambiente de trabalho e, assim, conseguissem ressignificar o sentido da própria carreira, de modo a permanecerem desenvolvendo suas atividades profissionais na instituição adquirente.

Com o detalhamento dos resultados obtidos por esta pesquisa, compreendeu-se que os funcionários, ao realizarem o processo de enfrentamento diante de uma situação adversa, não o fizeram apenas para não sucumbir à abrupta mudança no ambiente de trabalho, pois emergiram evidências nos relatos dos participantes de que os mesmos também deram início a um novo ciclo de suas carreiras. Isto indica que, ao reconfigurarem o significado da situação vivenciada, os funcionários encontraram maneiras de repensar a construção de suas próprias carreiras, pois a eles surgiram novos objetivos e metas, bem como estratégias para concretizá-las em face do processo de enfrentamento que realizaram na operação de aquisição.

A formação acadêmica dos entrevistados despontou com um fator de proteção que os auxiliou nesse processo de reconfiguração do significado da operação de aquisição e, por conseguinte, no repensar de suas vidas profissionais. Enquanto para alguns, neste caso B2 e B3, a situação estimulou a cursar outra graduação ou um curso de especialização, para outro entrevistado (B6), não só o fato de possuir uma formação acadêmica Ihe possibilitou amenizar os impactos negativos gerados pela situação, mas, sobretudo, ter conhecimento de que nem todos os funcionários - os colegas de trabalho - possuíam uma condição acadêmica equivalente à sua, Ihe serviu como uma estratégia de enfrentamento para amenizar os impactos negativos gerados no ambiente de trabalho.

Os resultados acima apresentados levam a perceber que a carreira dos bancários participantes desta pesquisa foi reconstruída de maneiras diferenciadas após o processo de venda no Banco I. Dentre estas diferentes perspectivas, destacaram-se dois comportamentos: 1) aqueles que, diante da situação adversa, vivenciaram a oportunidade de iniciar um novo ciclo de carreira, com novos objetivos e metas e, consequentemente, planos de ações para concretizá-los; 2) e aquele que se sentiu seguro frente à mudança, por crer na sua experiência e preparação profissional que, segundo o mesmo, era superior à dos colegas.

Possivelmente, os funcionários que apresentaram comportamentos proativos, isto é, que interpretaram a situação como uma possibilidade para o início de um novo ciclo de carreira, o fizeram ao perceber que oportunidades de crescimento profissional dentro do Banco $\mathrm{N}$ eram exequíveis ou até mesmo por visualizarem a possibilidade de uma carreira alternativa, em outra instituição. Nestes casos, observou-se que a formação acadêmica foi empreendida como uma estratégia de enfrentamento para criar maneiras alternativas de se lidar com a situação, de modo que esta concepção proporcionou aos funcionários vislumbrarem a possibilidade de iniciarem novos rumos profissionais, ou seja, um novo ciclo de carreira. Isto fez com que a formação acadêmica fosse utilizada como uma estratégia de enfrentamento desenvolvida por meio de uma concepção alinhada à fase inicial de um novo ciclo profissional.

Já o funcionário que apresentou um comportamento mais alinhado à visão ou abordagem tradicional de carreira, o fez por se sentir seguro em relação à sua formação acadêmica que, segundo o mesmo, era superior à de seus demais colegas. Ressaltam-se, neste caso, a segurança em relação ao vínculo com a organização e a expectativa de linearidade na vida profissional, características essas que vão de encontro a uma concepção mais contemporânea de carreira.

Ao fim deste estudo, percebe-se que, ao serem interseccionados preceitos teóricos e dados empíricos, os resultados obtidos geram uma contribuição importante para a área de ensino em administração, pois ampliam o entendimento acerca da capacidade das pessoas superarem as condições adversas vivenciadas em ambientes de trabalho em transformação, por meio da formação acadêmica que, ao ser empreendida como uma estratégia de enfrentamento, proporcionou às pessoas, neste caso aos entrevistados, novas maneiras de pensar, reconstruir e sentir o seu fazer na vida profissional.

Não por acaso, os resultados desta pesquisa atribuem à formação acadêmica novos contornos, ao se obter a compreensão de que a mesma não atua somente como algo que assegura pré-requisitos para inserção no mercado de trabalho e/ou manutenção da carreira. Sobretudo, é um fator de proteção passível de ser transformado em uma estratégia de enfrentamento para lidar com as mudanças organizacionais, de modo que, neste processo, as pessoas terminam por ampliar as significações e maneiras pelas quais 
passam a empreender e conceber suas formações acadêmicas, sendo esta compreensão uma das principais contribuições desta pesquisa.

Esta contribuição incentiva o pensamento acerca do ensino de graduação no Brasil, pois é uma alternativa a ser considerada, pois, possivelmente, o atual processo de ensino superior no país vem criando condições para as pessoas conceberem novas significações quanto às suas formações acadêmicas ao empreender a vida profissional. Isto porque, como discutido nesta pesquisa, a formação acadêmica não está somente atrelada ao significado de ser um pré-requisito para o mercado de trabalho, ao passo que este elemento mostrou-se ser utilizado, por vezes, como uma estratégia de enfrentamento que auxilia as pessoas a lidarem com as abruptas mudanças no ambiente de trabalho, ao passo que, assim, elas conseguem reconfigurar os significados das situações vivenciadas nas organizações e da própria carreira.

Como toda pesquisa apenas aproxima-se da compreensão do fenômeno ao qual se propõe investigar, sabe-se que este estudo apresenta certas limitações. Uma delas é o fato de ter sido utilizada uma amostra composta por apenas três funcionários. Embora este aspecto possa evocar certa fragilidade empírica à pesquisa, ressalta-se que este recorte decorreu do delineamento proposto para realização deste artigo, quanto à sua composição amostral. Contudo, há de se reconhecer que um número maior de participantes de pesquisa favoreceria a obtenção de resultados mais substanciais. Outra limitação decorre do corte temporal utilizado na pesquisa, pois ao ser utilizado o corte temporal seccional, em face da coleta de dados em 2010, mas com perspectiva longitudinal, ao serem resgatados fatos vivenciados pelos funcionários desde o ano de venda do Banco I, ou seja, 2006, esta distância cronológica pode ter influenciado no conteúdo de seus depoimentos.

Contudo, a identificação das limitações deste estudo fornece condições de apontar sugestões para pesquisas futuras. Dentre as possibilidades, uma perspectiva importante é o confronto entre a pesquisa empírica e as premissas norteadoras da literatura disponível sobre os fatores de proteção, pois tais estudos, quando realizados com foco na formação acadêmica enquanto um fator de proteção, vêm a contribuir para o desenvolvimento do conhecimento acerca de seu processo de transformação em estratégias de enfrentamento no contexto organizacional. Portanto, o presente estudo também busca incentivar a criação de um estímulo à realização de outras pesquisas empíricas acerca deste fenômeno, para que, assim, investigações futuras possam responder a perguntas como as apresentadas a seguir:

- Quais elementos utilizados no processo de ensino de graduação contribuem para a formação acadêmica ganhar novas significações que passam a orientar as pessoas no modo como empreendem, repensam e constroem suas vidas profissionais?

- Como o processo de transformação da formação acadêmica em estratégia de enfrentamento realizado pelas pessoas influencia a configuração do ambiente de trabalho nas organizações em que estão inseridas?

- Existe relação entre o processo de transformação da formação acadêmica em estratégia de enfrentamento realizado pelas pessoas e o desempenho organizacional?

- Como a formação acadêmica, uma vez transformada em estratégia de enfrentamento, influencia as pessoas a iniciarem novos ciclos de carreiras?

Espera-se, por meio das contribuições geradas neste estudo, que se reforce o interesse de pesquisa sobre o fenômeno em contexto organizacional, de modo que, por meio desta prática na área de administração, atinja-se um ponto em que os pesquisadores já não tenham mais a necessidade de recorrer ao re-ensaiar da justificativa primordial para legitimar a relevância da temática e/ou o seu propósito geral de investigação. Ou seja, que tais estudos propiciam a compreensão acerca de como o elemento formação acadêmica está vinculado às experiências das pessoas, quando na vivência e na superação dos impactos gerados pelas abruptas mudanças no ambiente de trabalho.

Assim, se este estudo servir como um complemento que aprofunde as visões sobre o elemento formação acadêmica como um estratégia de enfrentamento em ambientes de trabalho em transformação, fora cumprida a sua principal finalidade, pois com sua realização, motivada a partir de aspectos inusitados que emergiram em uma pesquisa preliminar, buscou-se apontar mais uma alternativa para se ampliar a compreensão sobre o processo de enfrentamento realizado pelas pessoas, por meio da formação acadêmica, frente às situações adversas com as quais tem de lidar cotidianamente em suas vidas profissionais. 


\section{Referências}

Appolinário, S. (2006) Metodologia da ciência: filosofia e prática da pesquisa. São Paulo: Pioneira Thomson Learning.

Arthur, M. B., Claman, P.H., \& Defillipi, R. (1995) Intelligent Enterprise, Intelligent Careers. Academy of Management Executive, 9(4), 7-39. http://dx.doi.org/10.5465/AME.1995.9512032185

Arthur, M. B., Hall, D. T., \& Lawrence, B. S. (1989) Generating new directions in career theory: the case for a transdisciplinary approach. In: Arthur, M. B., Hall, D. T., \& Lawrence, B. S. (Orgs.) Handbook of career theory. New York: Cambridge University Press.

Arthur, M. B., Rousseau, D. M. (2001) Introduction: the boundaryless career as a new employment principle. In: Arthur, M. B., \& Rousseau, D. M. The boundaryless career: a new employment principle for a new organizational era. New York: Oxford University Press.

Barlach, L. (2005) O que é resiliência humana? Uma contribuição para a construção do conceito. 2005. 108 p. Dissertação (Mestrado em Psicologia Social) - Instituto de Psicologia, Universidade de São Paulo. São Paulo - SP.

Barlach, L., Limongi-França, A. C., \& Malvezzi, S. (2008) O Conceito de Resiliência Aplicado ao Trabalho nas Organizações. Internamerican Journal of Psychology, 42 (1), 101-112.

Barlach, L., \& Malvezzi, S. (2010) Human resilience: what is it? A conceptual review. Saarbrucken, Deutchland: VDM Verlag.

Bendassolli, P. F. (2009) Recomposição da relação sujeito-trabalho nos modelos emergentes de carreira. Revista de Administração de Empresas, São Paulo, 49(4), 387-400.

Bridges, W. (1995) Mudanças nas relações de trabalho. São Paulo: Makron Books.

Caldas, M. P., \& Tonelli, M. J. (1998) Chameleon men and managerial fads: a social and psychoanalytical approach to the 'fashionable mind'. In: Organizatinal Settings, Comunicação apresentada na Standing Conference of Organizational Symbolism.

Chanlat, J. F. (1995) Quais Carreiras e para Qual Sociedade (I)? Revista de Administração de Empresas, São Paulo, 35(6), 67-75.

Cooper, D. R., \& Schindler, P. S. (2003) Métodos de Pesquisa em Administração. 7. ed. Porto Alegre: Bookman.

Cowan, P. A., Cowan, C. P., \& Schulz, M. S. (1996) Thinking about risk and resilience in families. In: Hetherington, M. E., \& Blechman, E. A. (Orgs.) Stress, Coping and Resiliency in Children and Families, New Jersey: Lawrence Erlbaum Associates.

Duarte, M. F. (2010). Desenvolvimento De Carreira Na Indústria Criativa Cearense: Histórias De Vida De Mestres Da Cultura Do Artesanato. Dissertação (Mestrado em Administração e Controladoria) Universidade Federal do Ceará (PPAC - FEAAC/UFC). Fortaleza-CE.

Evans, P. (1996) Carreira, sucesso e qualidade de vida. Revista de Administração de Empresas, 36(3), 1422.

Greenhaus, J. H., \& Callanan, G. A. (1994) Career management. Orlando: The Harcourt Brace College Publishers.

Hall, D. T. (2002) Careers in and out of organizations. London: Sage Publications Series.

Hall, D. T. (1996) Protean careers of the 21st century. Academy of Management Executive, 10(4), 8-16. http://dx.doi.org/10.5465/AME.1996.3145315

Harrington, B., \& Hall, D. T. (2007) Carrer Management \& Work-life integration. London: Sage Publications.

Job, F. P. P. (2003) Os sentidos do trabalho e a importância da resiliência nas organizações. 2003. Tese (Doutorado em Administração) - Escola de Administração de Empresas de São Paulo da Fundação Getúlio Vargas (EAESP - FGV). São Paulo - SP.

Lazarus, R. S., \& Folkman, S. (1984) Stress, Appraisal, and Coping. New York: Springer.

London, M., \& Stumpf, S. (1982) Managing careers. Massachussets: Addison Wesley.

Martins, H. T. (2001) Gestão de carreiras na era do conhecimento: abordagem conceitual e resultados de pesquisa. Rio de Janeiro: Qualitymark.

Milkovich, G. T., \& Boudreau, J. W (200). Administração de recursos humanos. São Paulo: Atlas.

Minarelli, J. A. (1995) Empregabilidade: como ter trabalho e remuneração sempre. São Paulo: Gente. 
Minayo, M. C. S. (2001) Pesquisa social: Teoria, método e criatividade. Petrópolis: Vozes.

Moreira, D. A. (2004) O Método Fenomenológico na Pesquisa. São Paulo: Pioneira Thomson Learning.

Ribeiro, R., Trevisan, L. N., \& Guedes, R. M. (2009) Carreiras de Profissionais de Marketing com Atuação em São Paulo: Uma avaliação da atitude proteana e das condições do ambiente para o desenvolvimento de uma carreira moderna. Paper presented at the XXXIII ENANPAD, São Paulo.

Silva, A. L. (2010) O Processo de Transformação dos Fatores de Proteção em Mecanismos de Defesa em Contexto Organizacional. 2010. Dissertação (Mestrado em Administração) - Universidade Estadual de Maringá e Universidade Estadual de Londrina (PPA - UEM/UEL). Londrina - PR.

Tavares, E., Pimenta, R. C., \& Balassiano, M. (2007) Carreira no Futebol como Exemplo de Carreira sem Fronteira. Paper presented at the XXXI ENANPAD, Rio de Janeiro.

Tavares, J., Yunes, M. A. M., Szymanski, H., Pereira, A. M. S., Ralha-Simões, H., \& Castro, M. A. C. D. de. (2001) Resiliência e Educação. São Paulo: Cortez.

Triviños, A. N. S. (2007) Introdução à pesquisa em ciências sociais: a pesquisa qualitativa em educação. São Paulo: Atlas.

Veloso, E. F. R., Dutra, J. S. \& Nakata, L. E. (2008) Percepção sobre carreiras inteligentes: diferenças entre as gerações $Y, X$ e baby boomers. Paper presented at the XXXII ENANPAD, Rio de Janeiro.

Vieira, M. M. F. (2004) Por uma boa pesquisa (qualitativa) em administração. In: Vieira, M. M. F., \& Zouain, D. M. Pesquisa qualitativa em Administração. Rio de Janeiro: FGV. 